\title{
ARTIGO
}

\section{Alicerces da administração na construção do ensino e da pesquisa em Unidades de Informação}

\author{
The administration's foundation in the education and \\ research building process within Information U nits
}

Daniela Pereira dos REIS 1

Rosangela Formentini CALDAS

\section{RE S U M O}

Proposição da inserção dos conteúdos relacionados à Administração nos cursos de graduação em Biblioteconomia. Apresenta a experiência de reestruturação curricular do Departamento de Ciência da informação da Faculdade de Filosofia e Ciências da UNESP/Marília, que possibilitou a inserção da linha de pesquisa em administração nas unidades de informação. Considera ainda que, para o desenvolvimento dos conteúdos programáticos, são necessários processos adequados de ensino-aprendizagem, sintonizados com um paradigma que estimula a pesquisa docente e discente.

Palavras-chave: administração, linhas de pesquisa, unidades de Informação, ensino-aprendizagem.

\section{A B S T R A C T}

This paper proposes the insertion of the subjects related to the administration in the Library Studies program. It presents the curriculum re-structuring experience

\footnotetext{
1 Professoras Assistentes, Departamento de Ciência da Informação, Faculdade de Filosofia e Ciências, Universidade Estadual Paulista. Avenida H ygino Muzzi Filho, 737, Campus Universitário, 17525-900, Marília, SP, Brasil. Correspondência/Correspondence to: D.P.R. Reis. E-mails: danireis@marilia.unesp.br e rcaldas@marilia.unesp.br

Recebido em 22/4 e aceito para publicação em 8/7/2003.
} 
in the Information Science department of the School of Philosophy and Sciences at UNESP/Marilia, which made possible to introduce the research in administration as a subject of studies in the information units. The study also argues that the successful development of the program contents cannot do without adequate teaching-learning processes, in tune with a paradigm that stimulates teachers and students' interest in research.

Key words: administration, research areas, information units, teaching-learning.

\section{N T R O D U Ç Ã O}

No princípio de um novo século, as expectativas e esperanças das pessoas em relação a um mundo melhor, mais justo e igualitário unem-se às tentativas de melhoria nas organizações, onde o aumento da oferta e as normas e padrões específicos em seu oferecimento, ocasionam uma demanda muito mais seletiva, resultando agora em um objetivo de conquistar e manter seus clientes com produtos e serviços diferenciados.

Nessa linha de pensamento, as universidades também têm buscado a melhoria profissional de seus colaboradores para o alcance de um objetivo - a excelência na formação de seus clientes os alunos - futuros profissionais que colaborarão para atingir as mudanças almejadas para a sociedade. Para isso, torna-se necessário um fator básico em qualquer organização: uma boa administração.

De acordo com Chiavenato (2000), a administração é o processo de planejar, organizar, dirigir e controlar o uso dos recursos organizacionais para alcançar os objetivos de uma organização.

Saber interpretar e analisar os objetivos propostos pela organização é a capacidade de transformá-los em recursos eficazes e eficientes, para as determinadas áreas e seus segmentos. Resultados positivos, almejados e alcançados em um espaço de tempo estipulado, criando processos inovadores com projeções futuras visando a melhoria do capital humano, físico e local.

\section{RECURSOS EFICIENTESE E FICAZES}

Os recursos eficazes estão disponibilizados em atender as necessidades da organização, em sua melhor adequação ao ambiente, realizando atitudes corretas em atenção às possibilidades/materiais existentes, com os objetivos a serem atingidos, com uma otimização dos recursos para alcançar melhores resultados, concentrando-se em tomar posturas e decisões corretamente a fim de atender às necessidades organizacionais.

Os recursos eficientes concentram-se em procurar a melhor maneira para obtenção dos resultados idealizados pela organização, os métodos e procedimentos a serem utilizados da forma mais coerente na resolução dos problemas, com a atenção à manutenção/treinamentos necessários, concentrando-se em realizar e tomar qualquer postura e decisão corretamente e da melhor maneira possível.

A melhor tomada de decisão, utilizando-se dos recursos administrativos existentes, enfoca a melhor observação e conseqüentemente, a melhor utilização da informação organizacional, percebida como um valor, dada a possibilidade de vir a se transformar em inovação tecnológica. 
Neste cenário, a melhor utilização dos alicerces da administração possibilita mais autonomia das pessoas inseridas no processo, demandando nova postura dos educadores que estão lançando ao mercado os novos profissionais da informação. Conjugado ainda, aos modelos organizacionais e de gestão do trabalho, dentre outros, a flexibilidade funcional.

As mudanças em pauta suscitaram uma série de questões na área de informação tanto no que diz respeito "ao novo" perfil do profissional da informação, quanto à capacidade do setor acadêmico em fornecer uma resposta adequada ao mercado de trabalho, diante das novas atividades e incorporações exigidas.

A área de Ciência da Informação vê-se diante de um mercado com novas exigências, necessitando de uma respectiva adequação educacional e profissional em seus cursos, devendo observar o aprofundamento de estudos nas áreas de teoria geral da administração; gestão de pessoas; marketing em unidades de informação; organização e métodos e planejamento estratégico, com a melhor utilização e adequação das tecnologias de informação, a fim de que, os mesmos possam responder às demandas de qualificação deste mercado de trabalho.

Para Shanker (2001), o desempenho do ensino ocorre em três dimensões: o conhecimento; a inserção do aluno em ser capaz de entrar no mundo como cidadão participante e se desempenhar dentro da economia; e, o crescimento e a participação do indivíduo na vida cultural da sociedade.

Dessa maneira, pensamos em formas e meios que consigam fixar essas prioridades expostas em um campo consciente da realidade existente no dia-a-dia das aulas e em sua possível realização na ligação entre o aluno e o professor.

O conhecimento perpassa a esfera única do momento, mas vê-se diante do quadro advindo das informações e dados obtidos e necessários para colocações realizadas ao meio, em um dado período de tempo para exposição de tema.

A capacidade de entrada no mundo, enquanto desempenho de um participante, é o ponto no qual o aluno coloca suas necessidades e capacidade de realização pessoal e profissional em estágios, laboratórios para práticas que vivenciem a realidade, estudos de casos com questionamentos levantados para serem debatidos em grupo; visitas e exposições de profissionais de áreas diferenciadas; solução de problemas advindos de situações reais e divulgadas por organizações por meio de relatos em periódicos; enfim, a preocupação em perceber a melhor maneira da inserção do aluno em um futuro profissional, faz-nos repensar sobre o papel que cada disciplina desempenha em sua formação.

A participação na vida cultural faz-se presente nas visitas dos alunos, realizadas às organizações enquanto sujeito participante do meio, aliadas às teorias estudadas em sala de aula e mencionadas em debates e comparadas com a prática profissional nas visitas técnicas, juntamente com a assimilação dos temas a partir de vídeos trabalhados (filmes educacionais e comerciais), e através da divulgação da pesquisa em eventos.

A utilização das tecnologias de informação, junto à preocupação com um novo meio de comunicação, facilita experiências de aprendizagem complexas e cooperativas e requer um novo pensamento acerca da aprendizagem e da pesquisa. A busca pela melhoria do indivíduo na organização está associada a essa efetiva preocupação com as posturas ligadas à estratégia de aprendizagem pessoal e organizacional. O processo de um melhor entender as organizações e seus anseios, configura-se a partir do leque de informação existente e sua real necessidade para os diferentes parâmetros.

Ao se pensar no ensino da administração para os futuros bibliotecários, necessária se 
torna uma reflexão sobre os pontos realmente importantes para a vida profissional. Nesse sentido, a linha de pesquisa Administração em Unidades de Informação, do curso de Biblioteconomia da UNESP, Marília, tem somado esforços para que os alunos obtenham uma visão ampla do que seja atuar em uma unidade de informação, vislumbrando o planejamento, a organização, o controle e a direção.

Parte-se então do embasamento teórico, que configura o alicerce da administração, ramificado para a utilização das tecnologias informacionais, como estratégias no aperfeiçoamento do indivíduo, enfocando a gestão como insumo no processo de melhoria das ações realizadas em nível organizacional.

As pesquisas dessa linha vêm suprir uma necessidade existente no âmbito institucional acadêmico, a qual refere-se ao suprimento de uma consolidação no ensino, pesquisa e extensão, a partir do momento em que se tornam um conjunto de atividades complexas, as quais exigem a sinergia dos variados tipos de conhecimentos e habilidades dos docentes envolvidos com a política da própria instituição, através de publicações; da pesquisa trienal - projeto de pesquisa individual desenvolvida e apresentada ao término de três anos; orientações em monografias; coordenações de laboratórios auxiliares na pesquisa; palestras e conferências.

\section{A IM PLA N TAÇ ÃO D O NOVO C U R R Í C U L O}

O curso de Biblioteconomia da Faculdade de Filosofia e Ciências (FFC) da UNESP, Marília, no decorrer dos seus 25 anos, passou por reestruturações curriculares sendo que a última culminou com a implantação do novo currículo, em 1997.

No ano de 2000, com a abertura de concursos para docentes na FFC, especificamente, junto ao departamento de Ciência da Informação, foi possível a contratação de dois professores direcionados às disciplinas voltadas à administração, permitindo a reformulação dos planos de ensino. As bibliografias e metodologias aplicadas foram revisadas e atualizadas, embasadas na última reestruturação curricular, possibilitando a quebra de disciplinas com pré-requisitos, que anteriormente eram aplicadas. O objetivo foi a atualização de matérias e disciplinas de Formação Profissional em uma subdivisão de Administração de Bibliotecas, anexas à Resolução UNESP/97 .

Nessa ocasião, deu-se maior ênfase às disciplinas voltadas à Administração das Unidades de Informação (Quadro 1).

A criação das disciplinas, discriminadas como optativas (Quadro 1), tem um cuidado específico, serem disciplinas provocadas em conseqüência das necessidades e estímulos despertados pelos alunos, em discussões e

Quadro 1. Disciplinas da linha Administração em Unidades de Informação.

\begin{tabular}{ll}
\hline Disciplinas & Tipo \\
\hline Desenvolvimento do Trabalho Científico & Obrigatória \\
Dinâmica organizacional & Obrigatória \\
Marketing em unidades informacionais & Obrigatória \\
Organização e métodos & Obrigatória \\
Planejamento em Unidades da Informação & Obrigatória \\
Teoria geral da administração & Obrigatória \\
Criação e desenvolvimento de Empresa Júnior & Optativa \\
Elemento de gestão de qualidade & Optativa \\
\hline
\end{tabular}


questionamentos quer sejam em orientações de pesquisas, ou em sala de aula.

Até dois anos atrás a linha de pesquisa Administração em Unidades de Informação encontrava-se sem professores especialistas da área administrativa, pois os anteriores, responsáveis pela elaboração do plano de ensino, programa e ementa da disciplina encontravam-se em processo de aposentadoria e afastamento. Assim, a linha de pesquisa ficou enfraquecida, reduzindo a produção científica por parte dos docentes e dos alunos do curso de Biblioteconomia.

Além disso, uma presente inquietação do Departamento e o desafio de fortalecer tal linha com pesquisas e projetos científicos, foram passados aos novos docentes que, ao se engajarem no curso, já o fizeram como orientadores de pesquisa dos alunos. Portanto, o desafio foi adotado e considerado pelos novos membros dando abertura a uma nova fase para a linha de Administração em Unidades de Informação.

Conseqüentemente, a pesquisa se inseriu no universo do aluno o qual é capaz de construir o conhecimento da área de Administração em Unidades de Informação, em uma realidade vivida e estudada por eles próprios. Os projetos de pesquisa são fundamentados em idéias e conceitos de pesquisadores com relevante papel para a área de Ciência da Informação e vêm confirmar uma exigência do atual mercado de trabalho, como aponta Demo (1994, p.9), que se constitui em "aprender a aprender e saber pensar, para intervir de modo inovador, são as habilidades indispensáveis do cidadão e do trabalhador modernos, para além dos meros treinamentos, aulas, ensinos, instruções, etc.".

Para o mesmo autor, a igualdade buscada pelas pessoas menos favorecidas economicamente pode ser alcançada por meio de um instrumento decisivo, qual seja, "a habilidade de manejar e produzir conhecimento" (DEMO, 1994, p.33). Dessa maneira, aprender e ensinar a pesquisar constitui-se em ações de construção não só de conhecimento, mas de oportunidades mais justas para toda e qualquer pessoa que queira de fato, entrar e permanecer no mercado de trabalho.

Segundo Foucault (1992) a formação e a prática da ciência instauram-se de um movimento retrógrado e não de reagrupamentos independentes, com a necessidade de cumplicidade na instauração da ciência e do saber, com o domínio e análise do conjunto de dados já utilizados e vivenciados.

Os processos administrativos estudados, corroboram e combinam-se nas diversas práticas administrativas, com a finalidade de criar novos padrões e climas mais ajustados ao processo em movimento e vivenciados. Observando-se as circunstâncias, pois, para enxergar o melhor estilo de administração em qualquer ponto ou momento, deve-se deslocar o foco para a visão geral da estrutura inserida no processo. Mas, Hampton (1992) aponta que a visão geral pode negligenciar os detalhes, pois, atenta ao estilo global, sendo mais bem aproveitada quando da medida em que ajudam no trabalho a ser feito, constituindo-se em um padrão universal e absolutamente melhor.

\section{O NSIDERA ÇÕ ES FINA IS}

Neste sentido, o princípio do saber administrativo mais eficiente e eficaz, está na consciência de que não existe um tipo único de estilo a ser adotado, mas um tipo ajustado e apropriado, específico às situações vivenciadas. Enfatizando e enfocando a autonomia observada e resguardada quanto a iniciativa do departamento de Ciência da Informação quanto aos pesquisadores absorvidos na linha de pesquisa relatada.

Neste contexto, os alunos têm procurado os professores da linha com o interesse em pesquisar sobre os problemas e as possíveis soluções para as situações ocorridas nas 
unidades de informação nas quais trabalham, desenvolvem estágios ou vislumbram como futuro profissional. Entretanto, esse interesse pela linha não foi apenas por impulso mas um reflexo direcionado aos interesses nos novos docentes, e também desejo dos próprios alunos em investigar sobre os temas pertinentes à área.

Desse modo, a pesquisa individual de cada docente, os projetos de Trabalho de Conclusão de Curso (TCC) e pesquisas da bolsa institucional da Pró-Reitoria de Extensão Universitária (PROEX/UNESP) foram surgindo e sendo desenvolvidos, resultando em um constan-

\section{RE FER Ê N CIAS}

CHIAVENATO, I. Administração: teoria, processo e prática. São Paulo: Makron Books, 2000. 415p.

DEMO, P. Pesquisa e construção de conhecimento: metodologia científica no caminho de Habermas. Rio de Janeiro: Tempo Brasileiro, 1994.(Biblioteca Tempo Universitário, 96).

FOUCAULT, M. Arqueologia do saber. Petrópolis: Vozes, 1972. (Epistemologia e pensamento contemporâneo, 3). te insumo revigorante para a linha, para o curso e para o Departamento que agora consegue o envolvimento em uma área há muito vislumbrada.

Nos dois anos de trabalho da linha, frutos já podem ser vistos a partir da divulgação das pesquisas dos docentes e dos alunos que com eles se dispuseram a mostrar seus benefícios no tópico administração e a sua aplicabilidade para as unidades de informação, iniciando-se na transferência de conceitos e aplicação de estratégias, perpassando a melhoria no desenvolvimento de pessoas, com a visão nos produtos e serviços informacionais oferecidos.

HAMPTON, D.R. Administração contemporânea. São Paulo: McGraw-Hill, 1992.

RESOLUÇÃO UNESP n. 14 de 17 de fevereiro de 1997. Diário Oficial do Estado, p. 17, 18 fev. 1997.

SHANKER, A. Como tornar as escolas responsáveis. In: DRUCKER, P.F. Administração de organizações sem fins lucrativos: princípios e práticas. Pioneira: São Paulo, 2001. p.95. 